\title{
Review of models and actors in energy mix optimization - can leader visions and decisions align with optimum model strategies for our future energy systems?
}

\author{
Ruud Weijermars ${ }^{\mathrm{a}, *}$, Peter Taylor ${ }^{\mathrm{b}}$, Olivier Bahn ${ }^{\mathrm{c}}$, Subir Ranjan Das ${ }^{\mathrm{d}}$, Yi-Ming Wei ${ }^{\mathrm{e}, \mathrm{f}}$ \\ ${ }^{a}$ Alboran Energy Strategy Consultants \& Department of Geotechnology, Delft University of Technology, Stevinweg 1, Delft 2628CN, The Netherlands \\ ${ }^{\mathrm{b}}$ Centre for Integrated Energy Research, University of Leeds, Leeds, LS2 9JT, United Kingdom \\ ' GERAD \& Department of Management Sciences, HEC Montréal, 3000 Chemin de la Côte-Sainte-Catherine, Montréal, Québec H3T 2A7, Canada \\ ${ }^{d}$ Department of Strategic Management, University of Petroleum \& Energy Studies, PHD House, 4/2 Siri Institutional Area, New Delhi 110016, India \\ e Center for Energy and Environmental Policy Research, Beijing Institute of Technology, 5 South Zhongguancun Street, Haidian District, Beijing 100081, China \\ ${ }^{f}$ School of Management and Economics, Beijing Institute of Technology, 5 South Zhongguancun Street, Haidian District, Beijing 100081, China
}

\section{A R T I C LE I NFO}

\section{Article history:}

Received 23 October 2011

Accepted 24 October 2011

Available online 4 November 2011

\section{Keywords:}

Energy strategy

Energy vision

Energy scenarios

Energy mix

Future energy choices

Energy strategy decision-making

Corporate energy strategy

Energy strategy analysis

Energy strategy implementation

\begin{abstract}
A B S T R A C T
Organizational behavior and stakeholder processes continually influence energy strategy choices and decisions. Although theoretical optimizations can provide guidance for energy mix decisions from a pure physical systems engineering point of view, these solutions might not be optimal from a political or social perspective. Improving the transparency of our vision sharing and strategy making processes in a systematic way is therefore as important as the actual systems engineering solutions proposed by the modeling tools. Energy trend forecasting and back-casting, scenarios and system analysis have matured into powerful modeling tools for providing advice on optimizing our future energy solutions. The integrated use and iterative improvement of all these approaches can result in energy systems that become better optimized. Such an integrated approach is particularly important to those who have decision-making power over our future energy direction. Some of the challenges and opportunities for energy strategists that strive to promote optimal decisions on our future energy solutions are highlighted in this state-ofthe-art review.
\end{abstract}

(c) 2011 Elsevier Ltd. All rights reserved.

\section{Introduction}

Energy solutions for our past, present and future energy mixes are commonly formulated by stakeholders in a complex decision-making process. The principal 'actors' or stakeholder groups in our society responsible for achieving results in energy choices are identified in an IAC Report [1] as follows:

- Multinational organizations: IEA, UN, World Bank, regional developments banks, etc.

- Governments: national, regional, local energy policy makers.

- Science and technology community: academia and associations.

\footnotetext{
* Corresponding author.

E-mail address: R.Weijermars@TUDelft.nl (R. Weijermars).
}

- Private sector: industry, consultancies and foundations.

- Non-governmental organizations: World Energy Council, Earthwatch, etc.

- Media: Scholarly journals and Popular media (print, web, radio, TV)

- General public: social networks, etc.

Each actor considers strategy options, choices and plans. The outcome of the stakeholder process is at any one time based on historical commitments and investments, certain utility function assumptions, organizational behavior and is aided by contemporary conceptual and technology tools and models.

The societal significance of our future energy choices and resources prompts numerous additional questions: How do we know what a society's optimum energy mix is now and in the future? What utility function can be comprehensive and agreeable to all 
stakeholders? What have we tried so far in terms of engineering our energy future? What more should be done? Fortunately, politicians and corporate policy makers increasingly seek advice on these issues to ensure that they base their resources development and energy vision and strategy on sound knowledge. Regulatory policies have corrected energy markets from time to time, and arguably remain the prime drivers of the energy mix seen in many countries. However, not all actors will be prepared to share their energy vision and strategy plan. Enterprises, such as those acting as energy suppliers, must continue to build business value in today's competitive market. Nations and companies may therefore seek to maintain a competitive edge and they commonly benefit from leveraging some asymmetry in information.

The increasing environmental burden of energy extraction and conversion requires further scrutiny: Are we acting responsibly in our quest to maintain security of energy supplies? Can we mitigate the adverse effects of energy extraction on the natural environment? Gro Harlem Brundtland [2] definitely saw a need for top-down design of a vision for our use of natural resources: "The market is effective in directing resources, but less effective in promoting equity, equal opportunity and environmental requirements. These are needs defined by the people, and their political representatives."

Much has been said already about what would be needed to make the transition to a sustainable energy future. For example, the IAC Report [1] pointedly concluded: "The concept of energy sustainability encompasses not only the imperative of securing adequate energy to meet future needs, but doing so in a way that: (a) is compatible with preserving the underlying integrity of essential natural systems, including averting dangerous climate change; (b) extends basic energy services to the more than 2 billion people worldwide who currently lack access to modern forms of energy; and (c) reduces the security risks and potential of geopolitical conflict that could otherwise arise from an escalating competition for unevenly distributed energy resource."
The efforts to provide clean and secure energy supply around the world are speeding up [3]. Energy visions are commonly formulated by federal and regional authorities; options for improving the development of our choices on future energy supply, loss and use are continually evolving. Any energy strategy aimed at transitioning an energy system from a present state to a future state must be guided by a strong and inspiring vision. Fig. 1 highlights several possible energy solutions and emerging new technologies. Vision and leadership are increasingly needed to develop and direct the execution of the appropriate energy strategies. Realizing such visions help to promote certain energy options, while others may be phased out. We must strive to close any emergent gaps between practitioner choices and the optimum model solutions. Clearly, all actors will benefit from the optimization of our common understanding of the dynamics in energy visioning, strategy planning and execution. This brief review highlights today's major insights and the models available to guide the development of such energy visions and strategy plans.

\section{Earth's exergy fluxes}

Earth's total energy resource potential for future use can be quantified in an exergy analysis [4]. Exergy is released from four primary reservoirs: solar nuclear activity, gravitational mass, and Earth's thermal and terrestrial nuclear activity, as described by the second law of thermodynamics. The work potential relative to the reference state translates to an exergy flow when the physical and chemical states change. Most natural energy resources are secondary repositories of exergy and their energy content is practically identical to the exergy value [5]. Materials with higher purity commonly have lower entropy and therefore possess higher exergy and energy potentials. Exergy of fossil, nuclear and renewable reservoirs can be destroyed or converted into usable energy by chemical reaction (burning), nuclear reaction (fission and fusion) or mechanical and photovoltaic conversion of renewable sources. The total exergy flux

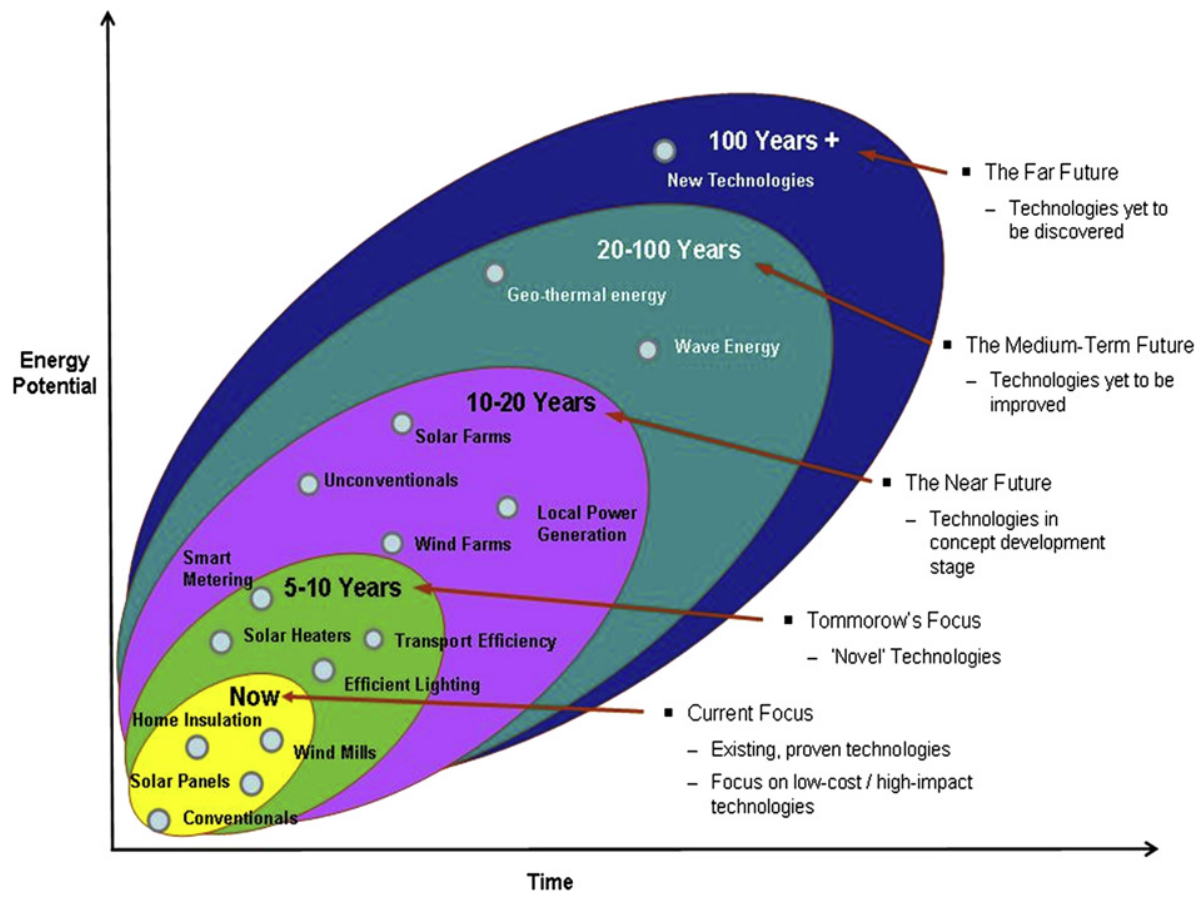

Fig. 1. Inventory of energy solutions for the present and future. Options are plentiful, but their realization and the right balance need to be optimized, based on vision and strategy for implementation. Plani-form ellipses are propagating timelines, non-dimensional. 
from source to natural and anthropogenic sinks, partly via intermediate fossil energy repositories, is concisely mapped in Fig. 2. The world's total energy consumption rate amounted to 14.61 Terawatts in 2007 or about 2250 Watt per person. The overview of Fig. 2 shows the physical system that governs exergy and energy flows.

The anthropogenic choices for tapping into the Earth's energy sources are commonly based on factors such as current technological capacity and future innovations. At any one time we have a complex setup of infrastructure enabled by capital investment that connects current energy supply centers with consumer markets. The technological learning curve continually expands the range of energy solutions shown in Fig. 1, while these seek to exploit the energy sources of the exergy flux shown in Fig. 2. As we move ahead, our future energy choices are increasingly directed by coordinated decisions involving demand forecast, cost and supply optimization, under constraints related to geopolitical and environmental issues.

\section{Forward trends in energy demand}

Energy producers and consumers have interacted for over 200 years (since the industrial revolution) with the aim of trying to match supply and demand effectively and at affordable prices. Primary energy use across the world has been projected to grow by an average of $1.7 \%$ annually, during the period 2010-2030 (Fig. 3a). This is only marginally lower than the growth of $1.9 \%$ recorded in the last two decades. Almost $93 \%$ of future global energy growth is contributed by the non-OECD regions, and their share will constitute about $67 \%$ of global consumption by 2030 [7]. This growth is driven by increases in both population (Fig. 3b) and GDP (Fig. 3c) The world's real income has increased by $87 \%$ in the last 20 years [8] and is projected to go up by another $100 \%$ by 2030 [7]. This will in turn lead to an increase in the global consumption of energy $[9,10]$, since although energy intensity (the energy used to produce one unit of GDP) is decreasing, this is not happening quickly enough to offset economic growth. The 9 billion population expected by the year 2050 will likely require $50 \%$ more energy than the Earth's current 7 billion inhabitants [11].

\section{Historic record of primary energy mix}

By tracking past and present global energy consumption and production, we know that the exploitation of the world's energy sources have followed an evolutionary shift that has led to the successful replacement of firewood and dung (traditional renewables), with fossil fuels: first coal, then oil and finally natural gas. Fig. 4 shows the past evolution in energy mix and one possible future scenario, in which the shares of nuclear and renewables grow rapidly at the expense of fossil fuels. In reality, the production peaks of fossil fuels have not yet occurred and their use is still growing according to recent trend forecasts [13]. Charting of absolute volumes shows that all fossil energy sources have steadily gained market volumes over the past century. For each of our fossil, nuclear and renewable energy carriers the absolute production volume has more than doubled over the past 40 years (Fig. 5).

The monitoring of global energy flows by international agencies is based on the records maintained by individual countries. Such records of energy consumption, production and imports provide a powerful basis for forward trend projections, which can underpin with quantitative data a country's vision for future energy supply and energy mix optimization. A granular model of a country-scale energy system may reveal excellent insight into how energy flows from source to end users, and also identifies what proportion of energy is lost in the process of energy conversion.

For example, the US energy flow from supply to consumption centers is compiled episodically by the US Lawrence Livermore National Laboratory [15] with an excellent granular resolution per fuel source and sink. Fig. 6 is a simplified version of the US energy flow schedule, and distinguishes energy sources, destinations and market shares of

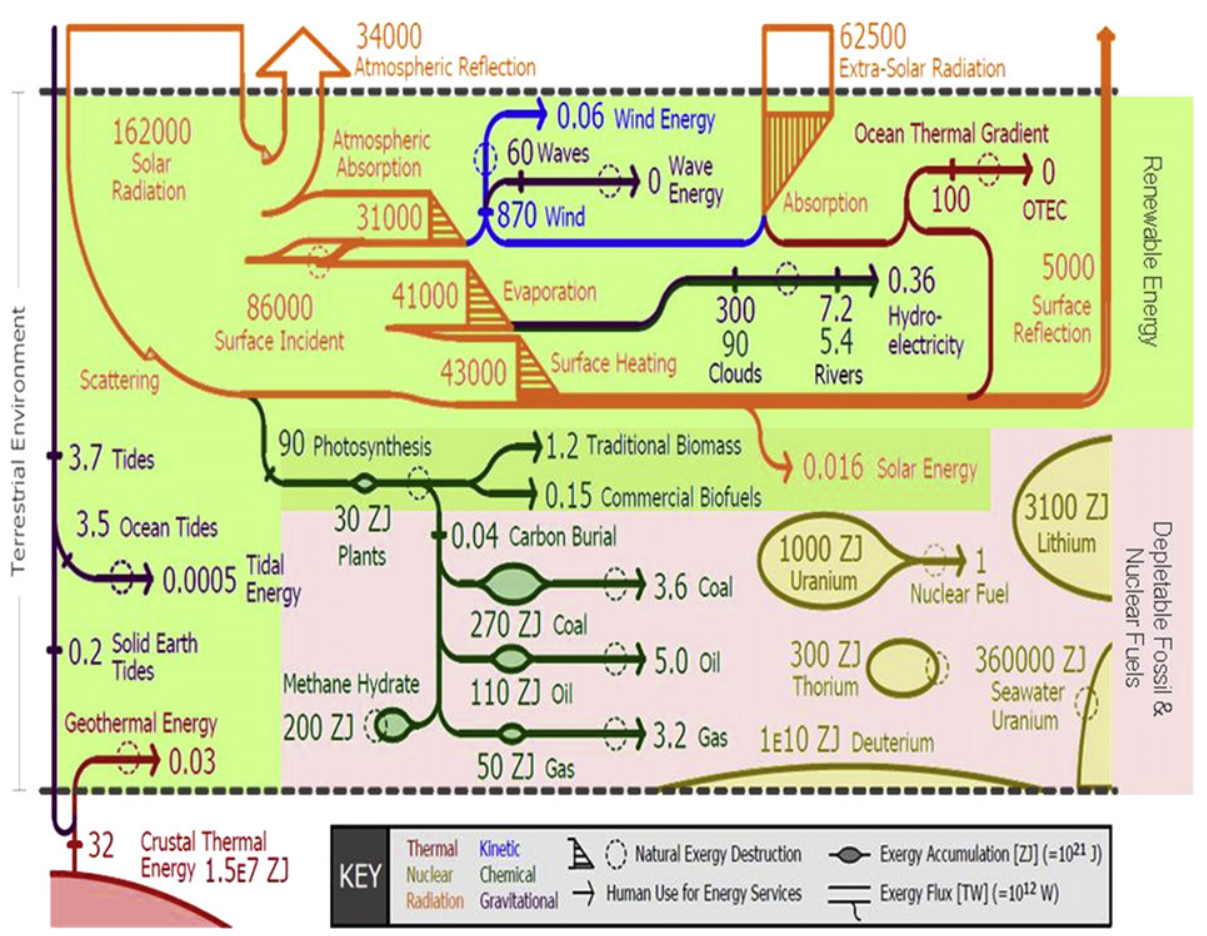

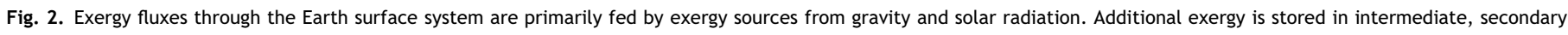
sources such as fossil and nuclear fuels. Only a fraction of the exergy flow and repositories is economically utilized by man for energy consumption (after Hermann and Simon [6]). 


\section{a Primary energy b Population c GDP}

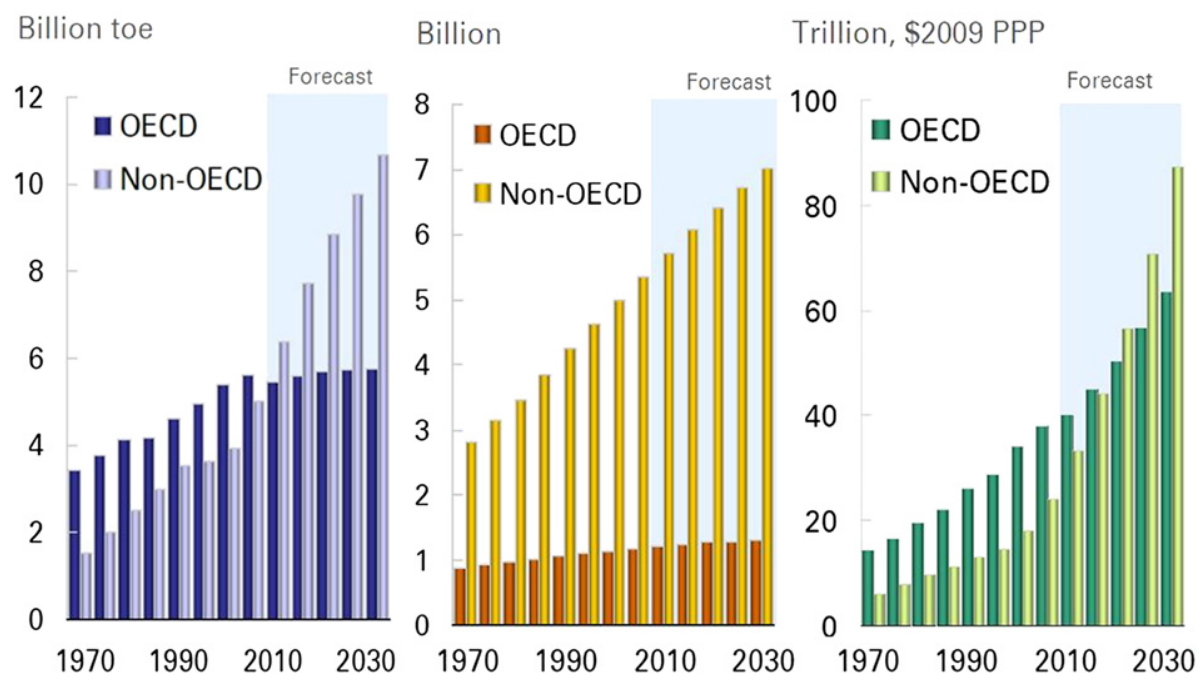

Fig. 3. Divergence in the global trends of OECD and non-OECD countries occurs in (a) Primary energy consumption growth, (b) Population growth, and (c) GDP growth [7].

end consumer groups, as well as losses in the energy supply system. It is useful to discuss the details and implications of US energy flows. Although other countries are equally important, the US energy system provides a useful reference for energy systems and energy mixes developing elsewhere.

The US consumes $22 \%$ of the 2008 world's primary energy sources (some 99.7 Quads of the 450 Quads world total). In 2009, primary energy supply in the US was composed as follows: $83 \%$ from fossil fuel sources (petroleum 37\%, natural gas $25 \%$, and coal $21 \%$; Fig. 6). The remaining $17 \%$ of the US primary energy supply is accounted for by nuclear energy $(9 \%)$ and renewables ( $8 \%$; as follows: biomass $4 \%$, hydropower $2.8 \%$, wind power $0.7 \%$, geothermal energy $0.4 \%$ and solar energy $0.1 \%$ ). An immediate split is seen, as the energy flows toward the consumption markets (Fig. 6), between energy supply for electric power generation, which consumes $40 \%$ of all primary energy in the US energy system, and the transportation segment portion taking $28 \%$ of

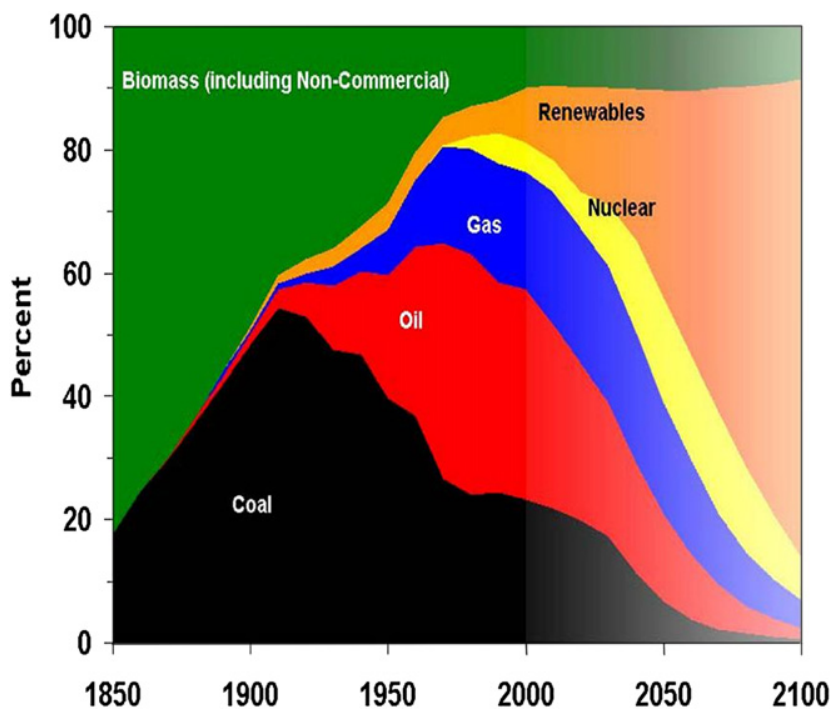

Fig. 4. Past energy mixes and a possible forward scenario for the 3rd Millennium (based on models by IIASA [12]). primary energy; all of the remaining $32 \%$ of primary energy is directly consumed by industrial, residential and commercial end-users. These three end users receive electric energy as well; which after conversion and losses in the power supply system brings - in the form of effective secondary electric energy - an additional $13 \%$ of primary energy to industrial, residential and commercial end-users.

The three principal consumer groups (industrial, residential and commercial end-users) jointly receive and consume $45 \%$ of the US primary energy supply (32\% primary energy plus $13 \%$ primary energy converted to electricity remaining after subtracting conversion losses). The transportation segment consumes an additional $28 \%$ of US primary energy. In total $27 \%$ of primary energy is lost in the power generation and transmission system to end consumers. An additional $31 \%$ of energy loss (heat dissipation, etc.) occurs in the energy

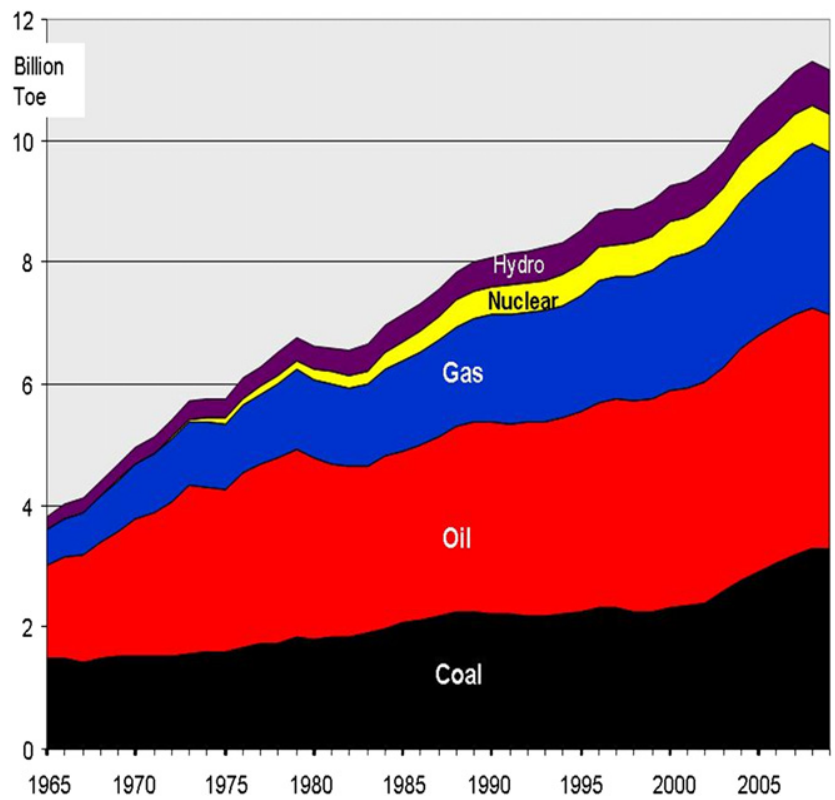

Fig. 5. Growth in major primary energy sources (in Ton Oil Equivalents) in addition to traditional biomass over the past 44 years (after BP [14]). 


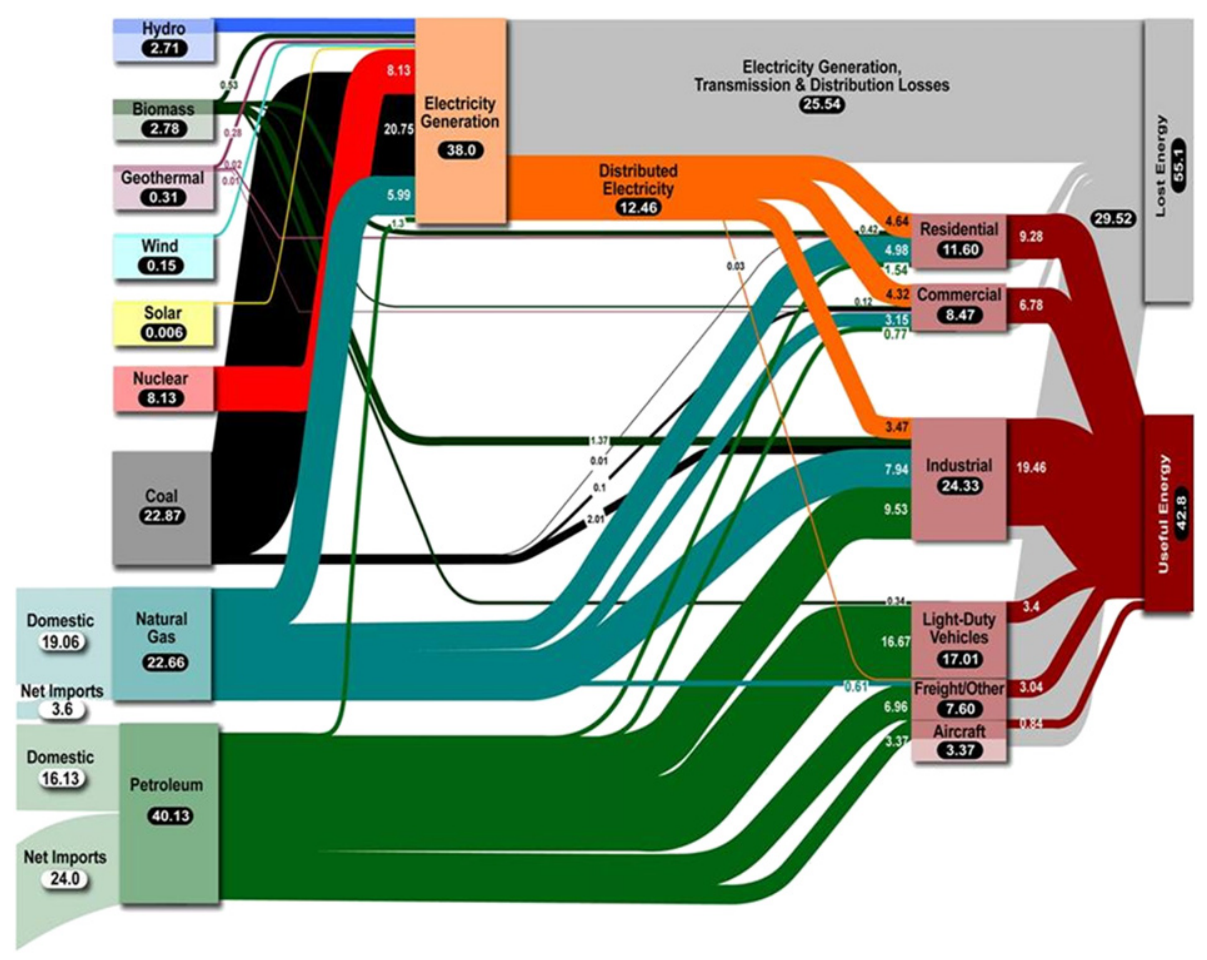

Fig. 6. Energy flow (Quads) through the US energy system from source to sink in a Sankey diagram, which represents proportional energy flux magnitude by relative arrow width (after Lawrence Livermore Laboratory [15]).

conversions applied by all end users of primary energy (transportation sector plus three consumer groups). This effectively means $58 \%$ of all primary energy goes into process losses and only $42 \%$ remains effectively available for use in the energy applications of the end consumer. The energy flow schedule in Fig. 6 also shows that most primary energy is lost in power generation and in transmission systems (28\%) and in the transportation segment (21\%), with the remaining $9 \%$ of primary energy lost in inefficiency of the energy conversion appliances of the three user groups (industrial, residential and commercial end-users).

Clearly, transportation is an inefficient energy conversion process and so is the conversion of primary energy into electric power (Fig. 6). Local power generation will help to reduce transmission losses and will benefit the competition in power fuel between coal and other fuels; smart grids are needed to help spread the loads. The price of coal versus alternatives will makes it hard for cleaner fuels to win market share in the absence of strong environmental policies. Fossil energy sources compete on price and reputation with renewable alternatives, and inter-fuel competition has intensified.

\section{Emergence of energy system models}

The advent of enhanced computer power and programming capacity and the 1st Oil Crisis of the 1970s created the need for models to quantify the interdependent effects of energy sector changes and economic performance of regional and world markets. The focus of early models was on the impact of an oil crisis on the economy and generation of possible options for adaptation. Such optimization models under constrained energy choices were developed in the US (NEMS at DOE), Europe (EFOM at the European Commission) and through international collaboration (MARKAL at the IEA and MESSAGE at IIASA).

More recently, the concern about energy supply security and cost has been expanded with a concern about responsible management of our environment. The combustion of various kinds of fuels (mainly fossil fuels) has indeed adverse effects on the environment with local, regional and global impacts. The incomplete combustion of hydrocarbons may for instance yield carbon monoxide that could reach toxic levels over urban centers. This phenomenon corresponds basically to a local pollution. Acid depositions (acid rains), triggered by sulfur dioxide and nitrogen oxides coming from the use of sulfurrich fossil fuels, correspond to regional air pollution, affecting large areas in Europe, North America and Asia. By contrast, the combustion of fossil fuels, through the release of so-called greenhouse gases (GHGs) such as carbon dioxide $\left(\mathrm{CO}_{2}\right)$, has a global impact on the Earth's climate.

GHGs emitted by the energy sector accumulate in the Earth's atmosphere, increasing the natural greenhouse effect. The thicker this blanket of GHGs, the higher the amount of infrared radiation that remains trapped, and the higher the increase of the Earth's temperature. The IPCC [16] reports in particular that temperature has already increased by about $0.8{ }^{\circ} \mathrm{C}$ since the pre-industrial revolution. GHGs concentration is now increasing at accelerated rates in our planet's atmosphere, and it is likely that atmospheric $\mathrm{CO}_{2}$ concentration increases twofold or threefold from the pre-industrial level in the absence of specific policies (energy policies, in particular) to $\mathrm{curb} \mathrm{CO}_{2}$ emissions [16].

Beyond global warming (an increase in the Earth's average temperature), various climatic changes are expected $[16,17]$ : changes in cloud cover, rainfall, wind flow patterns, timing of arrival of seasons such as monsoons. The frequency of floods, cyclones, typhoons will also change along with the intensity of the floods and droughts. Warmer temperatures lead indeed to greater evaporation in all regions, and a higher degree of precipitation in specific areas. Thus, dry regions of the planet may become even drier due to loss of moisture, and these droughts are likely to result in larger desert regions. In addition, overgrazing, denuded agricultural soils and deforestation continue and compound the pressure on the natural ecosystem of our planet [18]. 
Energy policy formulation and technology improvements can decelerate the growth of greenhouse gas emissions from energy use. But the slowing down is not happening at the right pace to create a safe carbon trajectory for our planet. The growth of emissions across the globe will slow down from 1.9\% p.a. in 1990-2010, to $1.2 \%$ p.a. for the period $2010-2030$ as OECD emissions will be lower in 2030 than in 2010 [7]. This decrease will be more than offset by the growth in non-OECD emissions (Fig. 3). More aggressive energy policies are required to ensure that GHG emissions will reduce from 2020 onwards [14].

The majority of the world's population is poor and lives in floodplains and slums around the modern cities. They do not have places to migrate to - unlike their ancestors - in search of new habitats. Therefore, the inhabitants of slums in both developed and developing countries could become the first victims of future catastrophes like floods, droughts and landslides caused by global warming [19]. The economic development of these regions will be driven by access to energy resources and must be accompanied by steps to arrest the root causes of the global warming.

\section{Models for engineering future energy mixes and climate change mitigation}

Today's global patterns of energy supply serve the needs of concurrent energy markets. Answering concerns about our future energy demand and supply, requires that we utilize theory, tools and models, on the basis of which we imagine a vision of the future and formulate a strategy to establish the desired energy mix that is suitable for the anticipated future. Several classifications can be used to distinguish among models used for formulating a strategy for future energy mixes [20]. In our review we highlight the following approaches:

- Forward projections of past econometric trends

- Scenarios unconstrained by quantitative models

- Specific energy market equilibrium models

- Mixed energy system analysis

- Normative scenarios analysis based on energy system models

- Esoteric visions of our energy future

The range of programs developed to model energy systems has expanded over the past few decades.

Ministers and policy makers do not have time to read the program codes of energy systems models, but the broader community of practitioners and researchers of energy systems must be able to build energy strategy plans based on state-of-the-art modeling approaches. They must also continue to question and validate the underlying assumptions. Models should maintain a high level of transparency in order not to be accused of being an obscure and 'eclectic' methodology. In this study, the most relevant contemporary model approaches (listed above) are briefly highlighted below. Our outline includes references to a number of major program codes, but does not claim to provide an exhaustive overview.

\subsection{Forward projection of past econometric trends}

The extrapolation of past energy consumption trends and shift in energy mix can be made based on expectation of wealth, population growth and energy conservation measures. Jaccard [21] has discussed a normative equilibrium model, and Fig. 7 provides an example of the energy mix and consumption volumes for 2050 and 2100 . The advantage of such normative extrapolations is their transparency; a disadvantage could be the strong guidance by previous track record. Trend forecasting by extrapolation of current relationships (e.g., between income - or GDP - and energy use) tends to focus too narrowly on business-as-

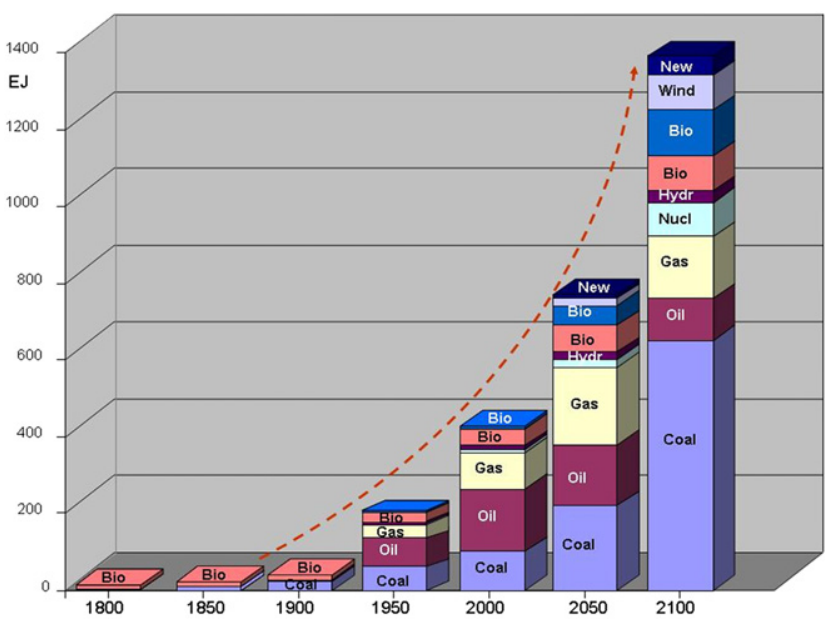

Fig. 7. Global energy consumption (Exa Joule) over time based on moderate population growth and moderate energy consumption per capita. Traditional biomass energy (pink) and modern biomass energy (blue) are indicated separately (plotted using data from Jaccard [21]).

usual. This can lead to alternative options and solutions for the future being overlooked. In any case, all future models, including forward models by trend extrapolation (Fig. 7) and scenario models (Fig. 4), may still differ widely for the year 2100 .

\subsection{Scenarios unconstrained by quantitative models}

Scenarios are possible futures that are built up from a consistent set of assumptions. Scenario thinking first emerged as a method during the Second World War. The method was refined for business strategy planning during the 1960s by Hermann Kahn and others at RAND Corporation [22] and the Stanford Research Institute (SRI). Shell's global scenarios in the 1970s became the official recognition of the method [23]. Strategy planning and scenario thinking are now widely used by companies, governments and others.

Scenarios can help to anticipate vulnerabilities in a strategy plan if the unexpected or unlikely adverse events were to happen, even though we don't really think it will happen. For example, it may be good to be prepared for the unexpected. What happens if the price of...'oil' exploded? Or what would our world look like without...'oil'? What would be alternatives? What would markets do regardless of the price of...'oil'? The occurrence of the unthinkable, unexpected event commonly provides both the biggest threat and the best opportunity, at the same time (Fig. 8).

\subsection{Specific energy market equilibrium models}

Equilibrium models use historic supply and demand (bottom-up) data streams to forward model future demand and supply equilibrium patterns. For example, the natural gas market is a subsystem of the global energy mix but can be considered a nearly closed value chain system with minor market share exchange with alternative energy sources. Natural gas market models aim to strip down the real world prototype studied to its fundamental architecture of supply and demand volumes and introduces critical parameters to describe the behavior of the market model. The market model then uses a base case or historic inputs to forward model the future market depending upon anticipated changes in the critical parameters governing the model output.

Most gas market models focus on equilibrium modeling of supply and demand with an objective function that aims to optimize economic 


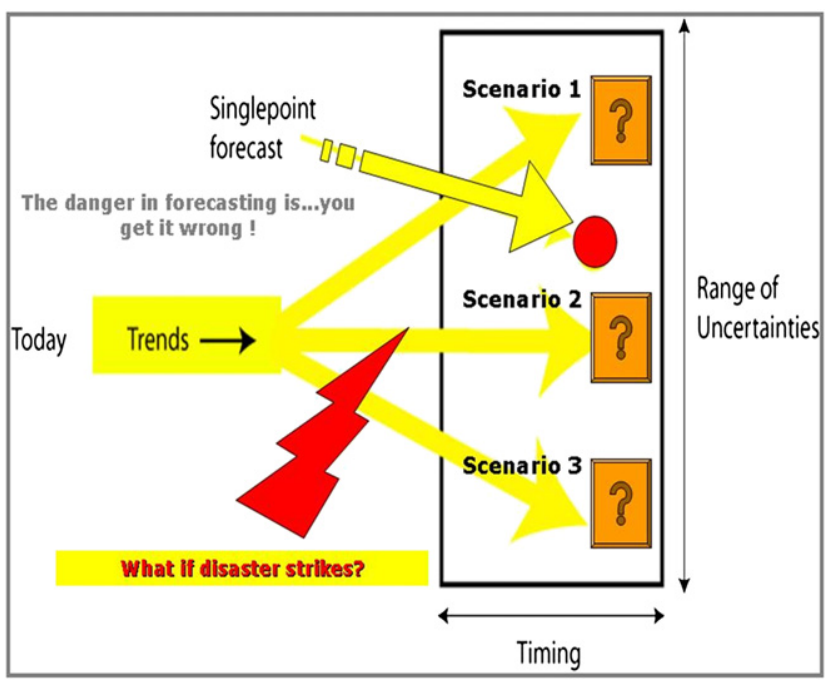

Fig. 8. Considering a broad range of scenarios enhances readiness to seize strategic options when disaster strikes or when the unthinkable happens. Scenario thinking helps to prepare for future strategy shifts, commonly triggered by anticipated and unanticipated changes in the global business landscape (after Weijermars [24]).

benefits for certain stakeholders in the natural gas system. For example, on the supply side new gas sources may be switched on (new fields, new pipelines, new LNG terminals) and at the demand side consumption may grow, drop or shift between regions and affect the market's internal gas balance. Improved understanding and quantitative insight in volume balance and price pressures is what gives gas models their added value. Beneficiaries of gas equilibrium models are the principal stakeholders in the gas value chain: gas producers, traders, utilities, service providers, transmission companies, and policy advisors.

Dynamic equilibrium models for regional gas markets initially could neglect the impact of changes in the global LNG supply patterns.
However, the emergence of LNG arbitrage and LNG spot gas means that regional gas markets models must now account for the impact of variable LNG supply. LNG spot gas shipped to the North Atlantic Basin affects gas supply patterns in both the North American and European gas markets (Fig. 9).

\subsubsection{US gas market models}

US based gas market models are commonly based on a physical framework architecture translated into a market equilibrium algorithm build into the so-called North American Regional Gas (NARG) model. An asset optimization software platform has been developed by Altos Management Partners, founded in 1995, under product name 'MarketBuilder'. The NARG model has been used for gas pipeline capacity assessments since 1983 and commonly uses a long-term, 45 years forecast horizon. The spatial resolution of data nodes in the NARG model improved over time as it has been used in numerous US studies. In 2001, A NARG based study by the US Western Interstate Energy Board (WIEB) contained 42 supply sub-regions in the US market [26].

The NARG model also provided the basis for expansion into what was then called the Baker Institute World Gas Trade Model (BIWGTM), which used data from the USGS [27] global natural gas supply inventory and economic demand algorithms to present an equilibrium model for the world market for natural gas until 2040. The model details and underlying gas demand algorithms are included in an Appendix of Hartley and Medlock ([28], pp. 389-395).

The full suite of NARG-based model tools developed by Altos Management Partners - including a BIWGTM influenced World Gas Model and MarketBuilder - was acquired by Deloitte Energy Consultants in 2011 to proceed as Deloitte MarketPoint. Rivaling products for the North American gas markets are available from Wood Mackenzie. Their North America Gas (NAGS) tool provides functionality similar to NARG. Both NAGS and NARG have been adapted to cover other world gas markets. A concise overview of additional academic US gas market models, some of which provided input for the DOE/EIA energy model framework NEMS (National Energy Modeling System), has been documented by Gabriel et al. [29].
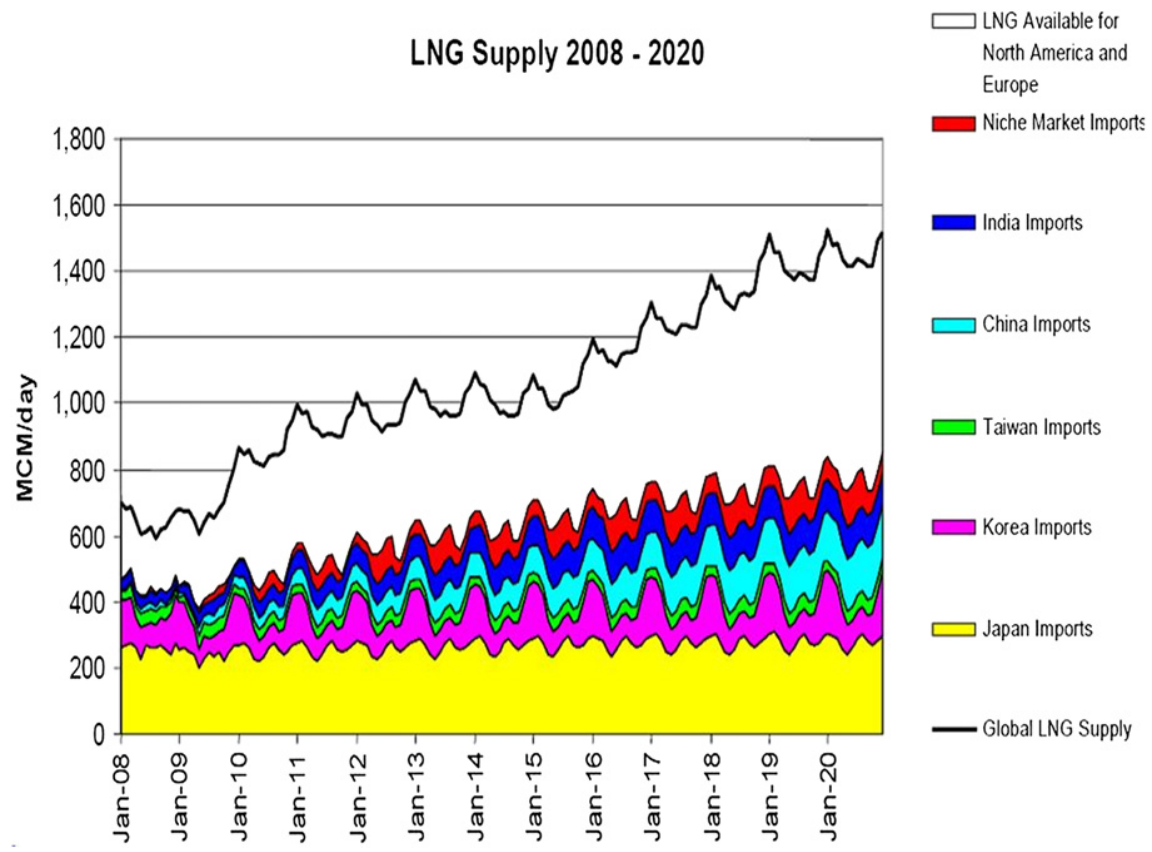

Fig. 9. Liquid natural gas (LNG) supply scenario based on LNG arbitrage model [25]. 


\subsubsection{European gas market models}

European gas market models have been initiated by several groups, but have hitherto lacked the continuity seen in the US modeling approach. Pre-liberalization models were published by Golombek et al. [30,31] to assess the potential impact of liberalization on the West European gas market. Follow up model setups were built by several groups of Dutch teams: ECN's GASTALE [32], CPB group's NATGAS [33], and TNO-NITG Thesis work ENETSIM [34]. The latter study used an agent-based economic optimization modeling framework following Tesfatsion [35], using a MATLAB model platform; the relevant algorithms appear in van Benthem ([34], pp. 58-68).

EU gas supply and demand balance were modeled by Ellis et al. [36] in a scenario approach for investment decisions and by Perner and Seeliger [37] to map the growing supply gap due to Europe's limited indigenous gas resources. The UK gas market was modeled by Pagliero [38]. Notably, market clearing equilibrium may be fast or slow, depending on liquidity in the market. One delaying mechanism is that part of Continental European market is still dominated by long-term oil-indexed gas contracts [39-42]. Such contracts tend to slow market-clearing as take-or-pay (TOP) decisions in are only taken periodically, namely when annual contract obligations are settled, commonly at preset clearance dates.

The extrapolation of supply-demand disequilibrium between the Nash-Cournot players to predict price trends is possible by using stochastic models [43-46]. Long-term price trends are routinely published by EIA and CERA. Remember that NYMEX futures provide a reflection of informed trader's bets and models for the future gas price as a result of progressive supply/demand market asymmetries.

\subsection{Mixed energy system analysis}

Analysis of energy systems takes place at numerous governmental, academic and corporate research institutions worldwide. Many models now use a modularized approach and some have evolved toward the modeling of scenarios for energy-climate interaction to support the IPCC work [16].

In the United States, the Energy Information Administration (EIA) of the U.S. Department of Energy (DOE) designed and continues to implement The National Energy Modeling System (NEMS) [47]. The main purpose of NEMS is to produce the Annual Energy Outlook, the closest the US has to official government energy forecasts, but it is also used by the EIA in studies for Congress and other Federal agencies. NEMS is also used by non-government groups, such as the Electric Power Research Institute, and a number of universities and private companies.

NEMS is a modular system, with each module representing a different fuel supply market, conversion sector, or end-use consumption sector within the energy system. The model incorporates delivered prices of energy to end users and the quantities consumed, by product, region, and sector. Other data includes economic activity, domestic production, and international petroleum supply. NEMS uses a market-based approach to energy analysis. For each fuel and consuming sector, the model balances energy supply and demand, accounting for economic competition among the various energy fuels and sources.

The time horizon of NEMS is currently to 2035, with the United States sub-divided into a number of regions, depending on data availability. For example, the end-use consumption modules use the nine Census divisions, whereas the electricity market module uses 15 supply regions based on those of the North American Electric Reliability Council.

The modular design of NEMS permits the use of the methodology and level of detail most appropriate for each energy sector. NEMS calls each supply, conversion, and end-use demand module in sequence until the delivered prices of energy and the quantities demanded have converged within tolerance, thus achieving an economic equilibrium of supply and demand in the consuming sectors. A solution is reached annually through the projection horizon.

Applications for which the EIA uses NEMS include analyzing the effects of existing and proposed government laws and regulations related to energy production and use; the potential impact of new and advanced energy production, conversion, and consumption technologies; the impact and cost of greenhouse gas control; the impact of increased use of renewable energy sources; and the potential savings from increased efficiency of energy use; and the impact of regulations on the use of alternative or reformulated fuels.

Another suite of models developed in the United States is based on ENPEP software [48]. This non-linear equilibrium model (Energy and Power Evaluation Program - ENPEP) matches energy demand with available energy resources and technology for different segments of the energy system. Basic input parameters include energy statistics on production and consumption in a base year and projected demand growth under any policy and technology constraints [48]. The model employs a market share algorithm to estimate the penetration of supply alternatives (Fig. 10). ENPEP is also expanded with decisionmaking models that include: MAED, WASP, SIMPACTS, ISED, MESSAGE, and FINPLAN. The World Bank, International Atomic Energy Agency (IAEA), US Department of Energy (DOE), Argonne National Laboratory (CEEESA) and a consulting firm (ADICA) all act as distributors for ENPEP software.

In Europe, the PRIMES energy system model has been developed by the National Technical University of Athens in Greece and used
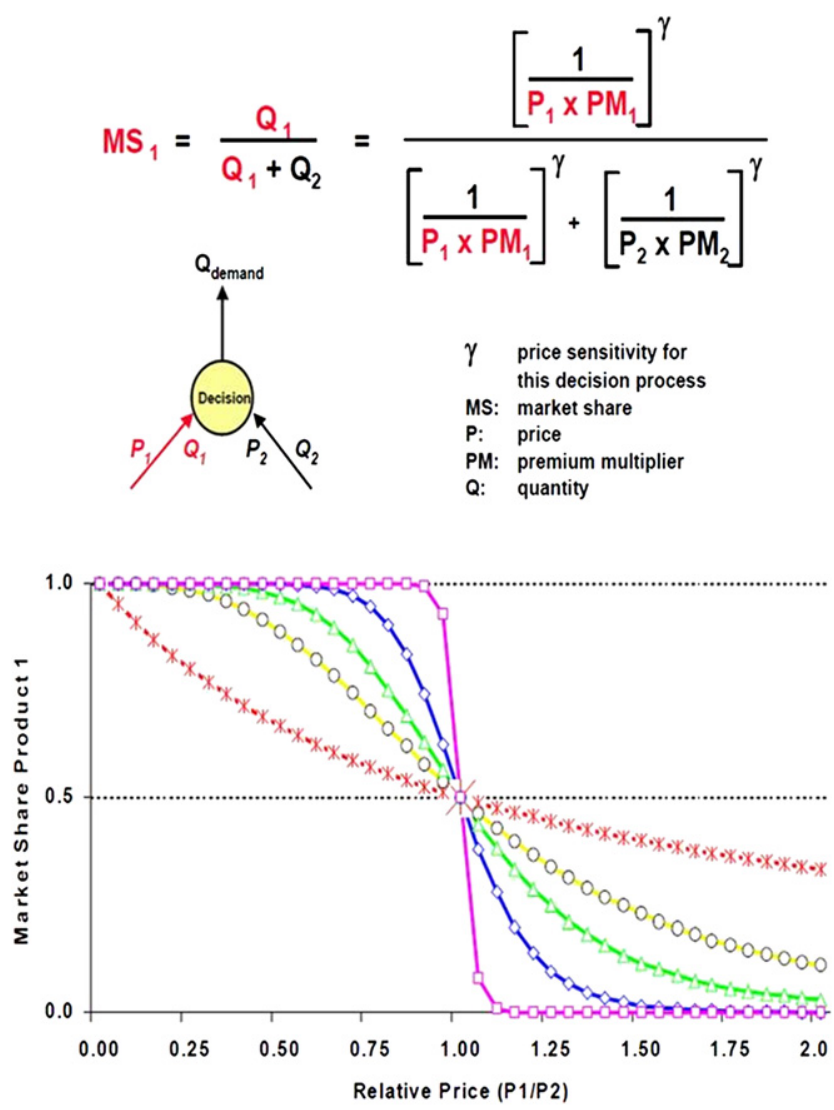

$-x-y=1-y=3-y=5-y=10-0-y=50$

Fig. 10. Fuel mix optimization based on cost and supply equilibrium development as used in ENPEP models [48]. 
extensively to support energy policy-making in the European Union for more than ten years [49]. Most recently the model is being used to generate a set of scenarios that will underpin the European Commission's Energy Roadmap 2050, part of the EU strategy for providing a long-term low carbon framework [50].

As in NEMS and ENPEP, PRIMES does not determine the energy mix using a global optimization function, but rather contains separate modules for each demand and supply sector and then finds market clearing by adjusting prices for each energy commodity such that the quantity producers find best to supply matches the quantity consumers wish to use in each sector. The equilibrium is static (within each time period) but repeated in a time-forward path, under dynamic relationships. The latest version of the model covers 35 European countries and over 25 different energy commodities. The sectoral and technological representation is also extensive and so the model is often considered as a hybrid, combining engineering detail with economic market-driven representations.

\subsection{Normative scenarios analysis based on energy system models}

Quantitative energy scenarios are commonly based on a set of assumptions that extrapolate current trends as a base case (businessas-usual option) and generate one or more alternative options to meet certain (top-down) future constraints imposed on energy use. Uncertainties may be accounted for in either a deterministic or stochastic modeling approach. The sensitivity analyses of parameters that are most crucial for the outcome of a specific scenario option can be generated making use of Monte-Carlo simulations.

For example, energy models by the IEA are based on computerized systems that were initiated in 1976 in international projects of system analysts. MARKAL, a linear programming model for energy systems analysis [51], provides the basis for the supply-side aspects of the IEA's normative scenarios. MARKAL was originally developed by Brookhaven National Laboratory (US) and Kernforschungsanalage-Juelich (Germany) partly under the governance of the IEA. MARKAL, a market allocation model, is often used for application at the level of an entire nation, and takes normative inputs for future market needs and determines the optimum energy mix and networks that can meet such a projected demand, subject to user-defined constraints e.g. a $\mathrm{CO}_{2}$ emission reduction target. Notice however that this modeling approach can also be used at a local (city), regional (e.g., European Union) and global (world) level.

Examples of normative energy scenarios are the IEA's 2008 and 2010 studies $[52,53]$ examining a $50 \%$ reduction in energy-related $\mathrm{CO}_{2}$ emissions by 2050 compared to 2005 levels. These scenarios were calculated to specifically advise OECD ministers on the cost of executing detailed future energy scenarios that would meet their stated long-term GHG emission reduction objectives. Renewables gain market share in these alternative energy scenarios and strategies to 2050. The fossil fuels' stake in the world's primary energy mix is steeply down-scaled in the most radical scenario option (Fig. 11): by 2050 global gas consumption is suppressed to $12 \%$ below the 2007 reference level, and oil supply is $27 \%$ lower (coal at $-36 \%$ ). The total annual cost of the fast switch to renewables was calculated in 2010 [53] to amount to USD 1.1 trillion (equivalent to Italy's current GDP or $1.1 \%$ of global GDP each year) from now until 2050. An undiscounted sum of over USD 46 trillion is needed (above the baseline cost for 2050 world energy supply) to establish a cleaner global energy mix by a combination of shifts in primary energy sources, increased energy efficiency, as well as innovations in energy technology. The IEA scenario studies [52,53] do not explicitly consider whether, in reality, the finance will be available to solve the GHG emission problem. The global economic recession of 2008/2009 has made governments reluctant to pursue the previously agreed mitigation measures that seem costly in the short-term, even if long-term

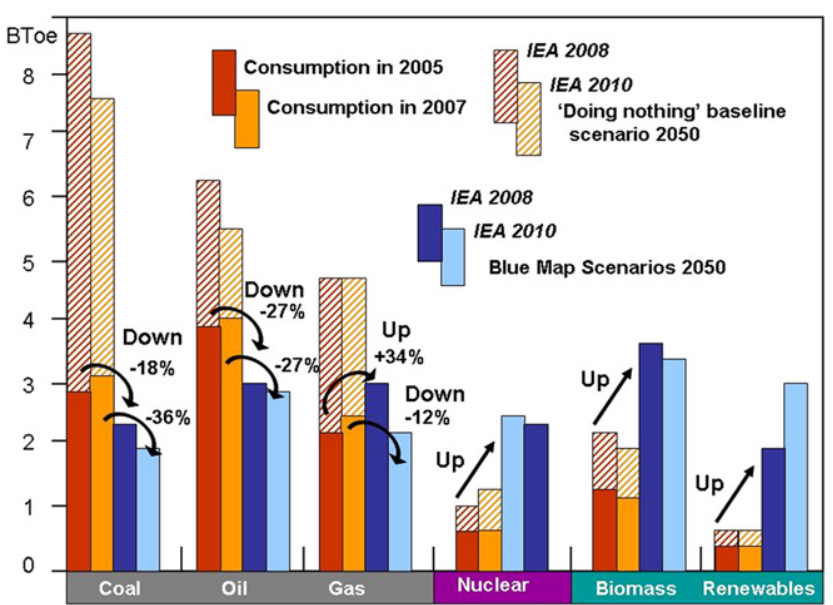

Fig. 11. Fossil fuels are scaled down in IEAs Energy Technology Perspectives fuel mix scenarios for 2050. Blue Map scenarios of 2008 and 2010 used 2005 and 2007 as baseline references, respectively. Units in billion Tons Oil Equivalent (after OECD/IEA [52,53]).

benefits may be much greater than in the absence of short-term economic sacrifices.

Meanwhile, nearly 70 countries have adopted the MARKAL programming model base and member country teams work together on alignment of tools, methods and training in the ETSAP consortium [54]. Aspects of MARKAL have more recently been combined with elements from EFOM (Energy Flow Optimization Model) in what is now named TIMES (The Integrated MARKAL-EFOM System). The full TIMES documentation is available in Loulou et al. [55]. MARKAL and EFOM share the same modeling approach and their merger provides a more flexible and powerful tool for optimizing the engineering of energy systems. A comprehensive summary of ETSAP results is given in a recent study [56].

Other normative energy scenarios have been derived using a combination of approaches. For instance, the European Climate Foundation published scenarios to investigate the feasibility of Europe achieving at least an $80 \%$ reduction in greenhouse gas (GHG) emissions below 1990 levels by 2050, while maintaining or improving today's levels of electricity supply reliability, energy security, economic growth and prosperity [57]. Their approach takes a baseline scenario from the IEA, but then uses a number of analytical tools, including cost-curves, to examine the potential for $\mathrm{CO}_{2}$ emissions abatement.

Alternative remedies for moderating emissions from fossil energy consumption for the UK are postulated by Mackay [58]; and further modeled by DECC [59]. The DECC 2050 Pathways work presents a framework through which to consider some of the choices and tradeoffs that the UK will have to make over the next forty years. It is different to most other studies in that it contains a web-based tool, which is designed to engage the general public and other stakeholders in the discussion of choices available to abate greenhouse gas emissions.

The application of energy system models to developing and emerging economies is increasing. In China, the Energy Research Institute under the National Development and Reform Commission (NDRC) uses a modeling system called IPAC that combines a number of different approaches. A recent high-profile study of greenhouse gas abatement for China made use of three IPAC models: a top-down computable general equilibrium (CGE) model, IPAC-CGE; a bottom-up technology-rich model, IPAC-AIM and an emissions model, IPACEmission [60]. Three scenarios were examined (Fig. 12). First, a business-as-usual scenario in which the main driving factor is economic development; second, a low carbon scenario, achievable through 


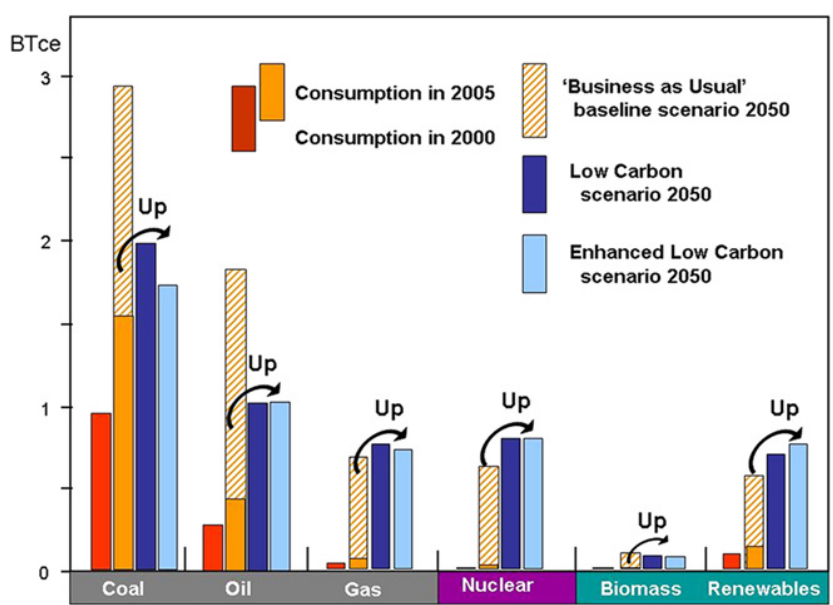

Fig. 12. Fossil fuels are growing in all primary energy mix scenarios for China toward 2050. Units in billion tons coal equivalent (after Energy Research Institute of NDRC [60]).

national policy interventions, taking into account factors such as national energy security, domestic environment and low carbon economy; third, an enhanced low carbon scenario realizable only through global joint effort which would accelerate technology development and allow faster cost reduction and wide deployment of key technologies such as carbon capture and storage (CCS). In the most ambitious scenario, Chinese $\mathrm{CO}_{2}$ emissions peak in 2030 before declining to 2005 levels by 2050 .

\subsection{Esoteric visions for the future}

Some energy visions are not necessarily constrained by past trends or contemporary energy system analysis. This is not always bad, especially if justified by a reason (analytical, emotional, ideological). For example, a region or community may opt for an emphasis on green solutions, accepting the extra short-term cost of an accelerated transition - or a mixture of these options.

Research can help to explore and stimulate the development of new solutions. For example, the introduction of the RPS (Renewable Portfolio Standards) [61,62] is aimed at increasing the renewable energy share in the US energy mix. A 2005 testimony for the US Senate Committee on Energy prepared by Lawrence Berkeley National Laboratory [63] recommended the diversification of power generation by stimulating renewable energy in order to reduce natural gas consumption and avoid outpacing supply by uncontrolled demand (mostly from power stations). The Lawrence study [63,64] recommended putting downward pressure on natural gas prices would benefit consumers by savings on energy bills. While the lowering of natural gas prices is true and theoretically correct, such a gas price reduction is not sustainable when it leads to well shut-in, decline of US gas transport infrastructure and premature life-cycle decline of the gas business - an appropriate balance must be found. The US Energy Policy Act of 2005 included the establishment of the Research Partnership to Secure Energy for America (RPSEA), a non-profit corporation of a consortium of premier US energy research universities, industry and independent research organizations. The RPSEA consortium has an annual R\&D budget allocation of 50 million USD for the next 10 years [65].

In any case, without an energy vision no conscious future energy strategy is possible. Maintaining the status quo is no option as the world around us is continually changing and a good energy vision addresses future challenges by offering ambitious solutions.

\section{Energy visions for future energy choices: challenges and opportunities}

\subsection{Corporate energy strategy}

Traditional strategy development in energy companies is a search for a strategic fit with the business environment with the aim to create value by exploiting opportunities using resources and competences [66]. This search usually leads to some form of competitive advantage for the business and its stakeholders. The strategy is translated into action by developing only the most profitable and suitable project options and by adequate resource allocation [67]. Today's energy producers are commonly led by the following utility principles: (1) global opportunities for making a profit (energy companies), (2) optimum strategy for national resources development \& monetization (government owned companies), (3) security of supply, and (4) geopolitical stability as business risk.

Many energy stakeholders improve their insight quantitatively in order to make decisions about the development of future options in a dynamic energy markets, commonly with an economic optimization objective. Individual energy corporations use the full suite of traditional strategy planning and execution methodologies. Their strategy plans are based on vision and translated into action by assessing suitable project options. At the corporate level, quantitative energy models are certainly needed to help reduce uncertainty in capacity allocation and to assess risk and opportunities associated with investment in energy assets. Improved understanding and quantitative insight in anticipated energy volumes and price pressures is what gives energy models their added value for energy corporations.

Market models can help to anticipate long-term and short-term energy needs and account for market liquidity problems due to bottlenecks in supply and storage capacity. Energy expansion projects are multibillion dollar propositions (e.g., Smart Grids, DESERTEC). These should be backed up with adequate modeling results to ensure that investments made are de-risked for undue dis-equilibrium effects in their respective market zones. Energy market models can also improve temporal resolution and understanding of short-term and seasonal behavior to predict price development in the market. For example, such seasonal changes dominate the gas and electricity markets. Utility companies and trading companies must make forward capacity planning for transmission and storage capacity allocation, as well as price hedging. Market performance can be highly volatile, and better models provide a basis for optimized decisions that can help improve their profit margins - primarily by reducing uncertainty.

\subsection{Public interest energy strategy}

Energy strategy practitioners know that it is difficult for leaders of nations and regions to develop a sound vision to guide their strategy choices for future energy supply and systems. Key questions remain: How do we know the right energy mix and energy consumption pattern in the future? Which technologies, knowledge, regulations and incentives are needed to support our strategy and develop a balanced energy mix? Which energy vision can guide us in future choices? How do we develop an energy strategy that can be successfully implemented? How well do the various fossil fuels and alternatives compare in bargaining power? Such questions are built into quantitative models used to aid decision-making on an optimal energy mix, as discussed below.

The development of energy strategies for nations and regions can benefit from elements of traditional strategy making principles. However, it is important to note the difference between decisionmaking for personal or small-group interest and that of society as 
a whole. The utility functions for energy optimization at the level of entire nations are not commonly aiming only for maximum corporate profit. Instead, the main concerns are to provide energy at affordable cost price for consumers, in a reliable and safe way and without supply interruptions. A national and globally oriented energy vision must help to cope with:

1. Vulnerability: safety, security of supply, supply interruptions, price stability, etc.

2. Environmental impact: pollution, sustainability issues, biodiversity, etc.

3. Resource constraints: finiteness of lifecycles, competitive cost

4. Competition for access to energy: 2 billion people worldwide currently lack access to modern forms of energy; $28 \%$ of the world's population consumes $2 / 3$ rd of our energy; or 3/4th of world's population consumes less than 1/4th of the available energy.

The vision must also anticipate, stimulate and support the development of truly relevant innovations and paradigm shifts that can change the future energy landscape. Successful execution of the energy vision requires building a shared passion for the vision and the choices and sacrifices to be made. Most strategies fail, not due to bad strategy design, but due to poor implementation. There is also another problem: sub-optimization due to local choices may be good for some, but not necessarily good for the greater benefit of all.

\subsection{Organizational behavior}

The optimum use of non-renewable and renewable energy resources can be theoretically solved by artificial intelligence models $[68,69]$. Such models simulate the powerful cognitive and sensory functions of the human brain and use this capability to represent and manipulate knowledge in the form of patterns. Based on these patterns neural networks, input-output functional relationship models have the potential for making better, quicker and more practical predictions than humans. However, in reality, decisions on energy strategy are affected by other issues involving many uncertainties that defy the logic of artificial intelligence.

Vision development and energy strategy decision-making processes are strongly influenced by organizational behaviors and cultures of organizations and nations. For example, in the US competitive market forces dominate over federal strategy blueprints. As a result, energy sources compete for market share, often stimulated by tax incentives, research stimuli and federal rules and regulations that foster and enhance fair competition. The US energy vision in part is to let market forces effectively compete to establish future energy mixes. Central planning tends to act only when the market fails to protect energy security, when whole fuel sources tend to vanish prematurely without incentives, or when fair competition becomes compromised in a particular energy sector.

In the EU, energy strategy is dominated by the EU's energy agenda [70] which focuses on switching to renewables, GHG mitigation and energy conservation. The target for 2020 has been 20-20-20: $20 \%$ reduction in energy consumption below 'projected'- levels, $20 \%$ of primary energy use should come from renewable sources, and GHG emissions should be reduced by $20 \%$ taking 1990 as the reference year. But there are other threats to Europe's future energy supply in need of attention too.

The strong focus on renewables arguably has diminished the EU's vigilance about the strategic security of its fossil energy supply. European oil and gas production have now both peaked.

Traditional oil and natural gas still account for a hefty $60 \%$ of Europe's primary energy demand [13]. Recent unrest in the MENA countries has reminded us that importing some $50 \%$ of its natural gas and $70 \%$ of its oil makes Europe rather vulnerable to price hikes and supply interruptions. Recent studies have argued that the EU must urgently adopt measures to counter the decline in the EU's security of oil and gas supply [71,72].

\subsection{Energy strategy planning and implementation}

The world's current energy mix has evolved and was determined by past utility perceptions, availability, market dynamics, organizational behavior and stakeholder processes. A vision for the future energy mix remains useless unless a strategy plan is formulated that tells us how we can realize the envisioned future. A code of conduct - what is permitted and what not - in realizing and executing the strategy is also part of a civilized approach. The principal actors identified in Section 1 (this review) are jointly responsible for creating our energy future and reducing the impact on our environment.

The Climate Crisis may catalyze changes in energy visions and likely speeds up the implementation of alternative energy resources. If a lethal non-alignment of society's energy mix and its environment would unfold, amendments to energy strategy should be made quickly. Accelerated changes to our energy systems may be needed to avoid a tipping point in the climate system (e.g., [73]). This may require rapid managerial learning at all organizational levels to steer away from the danger zone. The Climate Crisis resembles a 'burning platform' type crisis [74,75] or 'melting iceberg' situation [76], which commonly accelerates the sense of urgency to implement change. When the need for change is recognized with a higher sense of urgency, as advised by Kotter [77], then actors are more likely to respond swiftly to avoid the metaphorical crises of 'burning platforms' and 'melting icebergs'.

Although the Climate Crisis is urgent, it is becoming increasingly difficult at a time of world wide economic problems to raise sufficient support for tax increases and other measures to implement the necessary changes to our industrial and power generation plants. Governments commonly fear that the increased taxes required could lose them the next election. Industrial lobby groups argue that such changes would make them uncompetitive compared to overseas competitors. The larger nations therefore continue to emit large quantities of $\mathrm{CO}_{2}$ into the atmosphere. The $\mathrm{EU}$ has tried to implement a carbon credit system but the system has its problems, not least due to the interaction between emission trading and other policies.

The awareness of user groups and public interest in climate change has accelerated the need for models that help policy makers to achieve agreement between stakeholders in negotiations that aim for more responsible use of our natural resources. When energy visions are built, incomplete knowledge of complex energy systems may lead to suboptimum solutions from a systems engineering model perspective (Fig. 13). Some actors may make more insightful inferences and learn more quickly than others, but the intelligent use of rational tools and methods in energy vision development and strategy planning is advocated in this study.

\section{Discussion}

Many energy strategy studies have been published over the past decade by government agencies, NGOs, and international organizations. New studies continue to appear and are commonly momentous and voluminous - often comprising several hundred pages. The development of improved and globally shared visions for future energy solutions is advocated in this study. This remains crucial for the effective deployment of energy strategies for the future. 


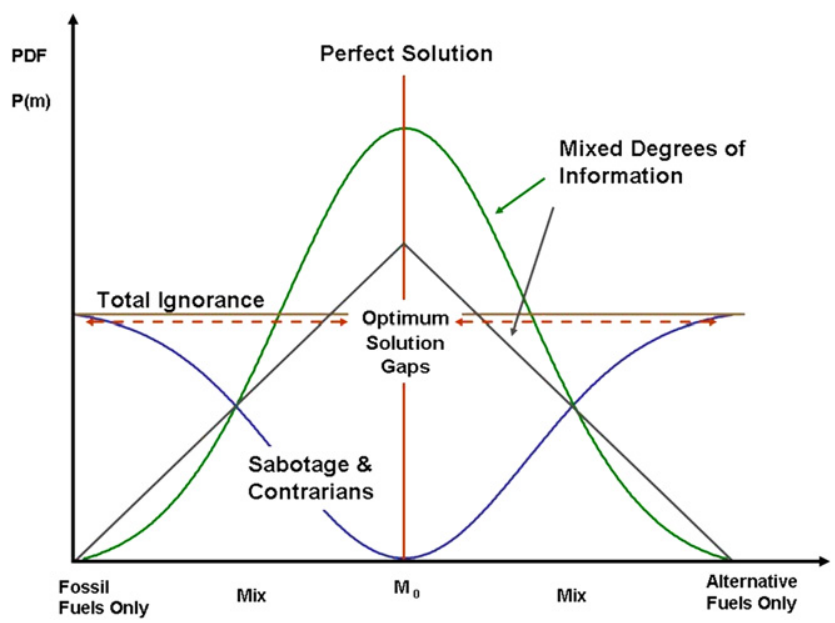

Fig. 13. Fuel mix optimization based on system analysis may deliver a perfect solution $\left(M_{0}\right)$. However, such solutions may be adopted or ignored, which leads to a mismatch or gap between the optimum and actual solution selected. The vertical scale represents the likelihood $[\mathrm{P}(\mathrm{m})]$ that the optimum solution will be adopted.

Four bottlenecks in vision sharing may consistently compromise the wider use and effectiveness of energy strategy studies by energy agencies, states, NGOs and other major organizations:

(1) From a practitioner's perspective, most clients are unable to quickly grasp the full meaning and interaction of the varied strategy studies. The essence of such studies is often only slowly absorbed and the impact of many strategy reports therefore remains minimal. Precisely the opposite is needed to achieve broad support and a successful implementation of new energy strategies.

(2) From an academic point of view, the basic premises of many strategy plans and energy scenarios are often encapsulated in complex models which rely on a huge amount of data and assumptions. In order to make things comprehensible most reports concentrate on only a few scenarios and often provide limited details on the models used and so do not clearly explain how sensitive results are to changes in most of the data. A much more extensive sensitivity analysis, plus further discussion of the underlying methodology, could help reveal which are the really important assumptions across all sectors and allow critical appraisal of the robustness of the results underlying the main conclusions.

(3) Numerous parallel strategy and scenario reports on energy strategy continue to appear from a variety of leading organizations (IEA, EIA, IAEA, WEC, OPEC, World Bank, etc.). These reports commonly are compiled by outstanding professionals. However, few of these reports are open to independent validation in the peer-review domain. A platform for critical appraisals and analyses of tools and methods would benefit and underpin the maturation of energy strategy as an emerging discipline - this is much needed.

(4) Energy strategy reports tend to be downloadable for free or at considerable cost (more the norm today than before). Their availability is limited, often due to websites renovating and removing links to former reports. Reports of five years ago or more are increasingly harder to obtain, which is not a desirable situation for research and analytical comparison of past and future trends in energy strategy.

These four barriers to concurrent strategy studies can be overcome through a new journal that can also serve as an alerting and analysis platform for new strategy reports. Energy Strategy Reviews fills this niche. This new journal stimulates the exchange and sharing of knowledge and best practice in energy strategy, planning and implementation. The target audience includes professionals from all stakeholder groups:

- Government institutions engaged in energy planning

- Energy agencies inventorying past trends and future energy scenarios

- Academic institutions working in energy research (both fossil, nuclear \& renewable)

- NGOs active in promoting future energy solutions

- Energy companies (upstream, midstream \& downstream)

- Energy strategy consultancy firms with practitioners' perspectives

The sharing of energy visions and strategy plans by organizations, corporations and states will contribute to establishing a common knowledge base for optimizing future energy choices.

\section{Conclusions}

Energy mix visions and strategies are determining an important part of our world's future prosperity and welfare. Choices made now are important for future generations. Energy trend forecasting and backcasting, scenarios and system analysis have matured into powerful modeling tools for providing advice on optimizing our future energy solutions. The choice of the model and its effectiveness for developing energy supply strategies critically depend on the underlying vision for achieving a future energy mix. This vision can be broad, such as letting market competition determine the future energy mix (e.g. the United States), or specific, such as aiming for an energy mix comprised almost exclusively of renewable sources (Iceland). The supreme role of a regional energy vision as the underlying basis for the planning of an energy strategy means that the strategy options derived from an energy system analysis point of view could concur with - or challenge - the premises of the energy vision. At best, the match between the vision and proposed strategy path is optimum for the subsystem covered at such a local scale. Consequently, the world's mix of energy resources will continue to be the aggregated result of regional, national and federal energy subsystems. Knowledge advancement and exchange are more important than ever before, because this will stimulate and optimize the vision sharing and further the integration of today's diverse energy strategies.

\section{List of abbreviations}

ADICA Smart Market ${ }^{\circledR}$ software provider

BIWGTM Baker Institute World Gas Trade Model

CCS Carbon capture and storage

CEEESA Center for Energy, Environmental, and Economic Systems Analysis

CERA Cambridge Energy Research Associates

CGE Computable General Equilibrium

CPB Centraal Plan Bureau

DECC Department of Energy and Climate Change

DESERTEC DESERTEC Industrial initiative

DOE Department of Energy

ECN Energie Centrum Nederland

EFOM Energy Flow Optimization Model

EIA Energy Information Administration

ENETSIM Energy NETwork SIMulator

ENPEP Energy and Power Evaluation Program 
ETSAP Energy Technology Systems Analysis Program

EU European Union

FINPLAN Financial Analysis of Electric Sector Expansion Plans

GASTALE Gas mArket System for Trade Analysis in a Liberalizing Europe

GDP Gross Domestic Product

GHG Greenhouse Gas

IAC InterAcademy Council

IAEA International Atomic Energy Agency

IEA International Energy Agency

IIASA International Institute for Applied Systems Analysis

IPAC Integrated Policy Model for China

IPCC Intergovernmental Panel on Climate Change

IQ Intelligence Quotient

ISED Institute for Social and Economic Development

LNG Liquefied Natural Gas

MAED Model for Analysis of Energy Demand

MARKAL MARKet ALlocation Model

MENA Middle East and North Africa

MESSAGE Model for Energy Supply Strategy Alternatives and their General Environmental Impact

NAGS North America Gas Model

NARG North American Regional Gas Model

NATGAS NATural GAS model

NEMS National Energy Modeling System

NGO Non-Government Organization

NYMEX New York Mercantile Exchange

OECD Organization for Economic Cooperation and Development

OPEC Organization of the Petroleum Exporting Countries

PRIMES Energy System Programmes supported by the European Commission

RAND Research ANd Development Corporation

RPS Renewable Portfolio Standards

RPSEA Research Partnership to Secure Energy for America

SIMPACTS SIMplified approach for estimating the environmental imPACTS

SRI Stanford Research Institute International

TIMES The Integrated MARKAL-EFOM System

TNO Technisch Natuurwetenschappelijk Onderzoek

TOP Take or Pay

UN United Nations

US United States

USD United States Dollar

USGS United States Geological Survey

WASP Wien Automatic System Planning Package

WEC World Energy Council

WIEB Western Interstate Energy Board

\section{References}

[1] IAC Report, Lighting the Way: Toward a Sustainable Energy Future, InterAcademy Council, 2007.http://www.interacademycouncil.net/ pp. 174

[2] G.H. Brundtland, Destination Norway - Commerce \& Culture (1996).

[3] IEA. IEA Clean Energy Progress Report http://www.iea.org/papers/2011/CEM_ Progress_Report.pdf, April 2011.

[4] W.A. Hermann, Quantifying global exergy resources, Energy 31 (2006) 1685-1702.

[5] G. Wall, Exergy - a Useful Concept within Resource Accounting, Report No. 77-42 See also:, Institute of Theoretical Physics, Goteborg, Sweden, 1977 http://www. exergy.se/ftp/paper1.pdf.

[6] W. Hermann, A.J. Simon, Global Exergy Flux, Reservoirs and Destruction, Global Climate and Energy Project at Stanford University, 2007.http://gcep.stanford. edu/pdfs/GCEP_Exergy_Poster_web.pdf.

[7] BP, 2011. Energy Outlook 2030.
[8] A. Maddison, Statistics on World Population, GDP and Per Capita GDP, 1-2008 AD (2009).

[9] International Energy Agency, Energy Balances of Non-OECD Countries, Paris, France, various editions up to 2010.

[10] International Energy Agency, Energy Balances of OECD Countries, Paris, France, various editions up to 2010 .

[11] United Nations Statistics Division, National Accounts Statistics (2011) New York, United States.

[12] N. Nakicenov, et al., Emissions Scenarios: a Special Report of Working Group III of the Intergovernmental Panel on Climate Change, Cambridge Univ. Press, Cambridge, U.K, 2000.

[13] International Energy Agency, World Energy Outlook 2010 (2010) Paris, France.

[14] BP, Statistical Review of World Energy. BP (2011).http://www.bp.com//bp/ statistical_energy_review/2010/statistical_review_of_world_energy_full_report 2010.pdf.

[15] Lawrence Livermore National Laboratory, Energy Flow Chart (2009).https:// energy.llnl.gov/informatics.php.

[16] IPCC. Fourth assessment report climate change; released in four distinct sections: (1) Working Group I Report (WGI): Climate Change 2007: The Physical Science Basis; (2) Working Group II Report (WGII): Climate Change 2007: Impacts, Adaptation and Vulnerability; (3) Working Group III Report (WGIII): Climate Change 2007: Mitigation of Climate Change; (4) The Synthesis Report (SYR). http: / /www. ipcc.ch/ipccreports/ar4-wg1.htm, 2007.

[17] Stern Report (Stern, Nicholas), Stern Review on the Economics of Climate Change, HM Treasury UK, 2006.http://www.hmtreasury.gov.uk/independent reviews/ stern review economics climate change/stern review report.cfm.

[18] R. Weijermars, Can we close Earth's sustainability gap? Renewable \& Sustainable Energy Reviews (2012), in press, doi:10.1016/j.rser.2011.07.085.

[19] Climate Change: Impacts, Vulnerabilities and Adaptation in Developing Countries, Climate Change Secretariat (UNFCCC), 2007.

[20] O. Bahn, A. Haurie, D.S. Zachary, Mathematical Modeling and Simulation Methods in Energy Systems, in Mathematical Models, from Encyclopedia of Life Support Systems (EOLSS), Developed under the Auspices of the UNESCO, Eolss Publishers, Oxford, UK, 2005.http://www.eolss.net.

[21] M. Jaccard, Sustainable Fossil Fuels. The Unusual Suspect in the Quest for Clean and Enduring Energy, Cambridge University Press, 2005, pp. 381.

[22] H. Kahn, W. Brown, L. Martel, The Next 200 Years: a Scenario for America and the World, William Morrow \& Company, New York, 1976.

[23] A. de Geus, The Living Company, Harvard Business School Press, Harvard, 1997.

[24] R. Weijermars, Building Corporate IQ: Moving the Energy Business from Smart to Genius. Executive Guide to Preventing Costly Crises, Springer-Verlag, 2011, pp. 336.

[25] H.V. Rogers, LNG trade-flows in the Atlantic Basin: trends and discontinuities, OES NG 41 (2010).

[26] M. Barmack, et al., A Regional Approach to Market Monitoring in the West. LBNL 61313 (2006).http://eetd.lbl.gov/ea/ems/reports/61313.pdf.

[27] USGS World Petroleum Assessment, http://pubs.usgs.gov/fs/fs-062-03/FS-062-03. pdf, 2000

[28] P.R. Hartley, K.B. Medlock III, The Baker Institute world gas trade model, in: A. Jaffe, D. Victor, M. Hayes (Eds.), Natural Gas and Geopolitics from 1970 to 2040 (2006).

[29] S. Gabriel, J. Zhuang, S. Kiet, A large-scale linear complementary model of the North American natural gas market, Energy Economics 27 (2005) 639-665.

[30] R. Golombek, et al., Effects of liberalizing the natural gas markets in Western Europe, Energy Journal 16 (1) (1995) 85-111.

[31] R. Golombek, et al., Increased competition on the supply side of the Western European natural gas markets, Energy Journal 18 (3) (1998) 1-18.

[32] M.G. Boots, et al., Trading in the downstream European gas market: a successive oligopoly approach, Energy Journal 25 (3) (2004) 73-102.

[33] G. Zwart, M. Mulder, NATGAS - A model of the European Natural Gas Market. CPB memorandum (2006).www.cpb.nl/sites/default/files/publicaties/download/ memo144.pdf.

[34] M. van Benthem, Optimizing The Structure of The Natural Gas Market Using an Agent-based Modeling Framework, Ph.D. Thesis, Rijksunivesiteit Groningen, 2010.

[35] L. Tesfatsion, Agent-based computational economics: a constructive approach to economic theory, in: L. Tesfatsion, K.L. Judd (Eds.), Handbook of Computational Economics, Agent Based Economics, vol. 2, Elsevier, 2006.

[36] A. Ellis, E. Bowitz, K. Roland, Structural change in Europe's gas markets: three scenarios for the development of the European gas market to 2020, Energy Policy 35 (2000) 227-237.

[37] J. Perner, A. Seeliger, Prospects of gas supplies to the European gas market until 2030 - results from the simulation model EUGAS, Utilities Policy 12 (2004) 291-302.

[38] M. Pagliero, Strategic interaction on the UK gas transportation system: the St. Fergus and Bacton constraints, Energy Economics 25 (2003) 345-358.

[39] J. Stern, Is there a rationale for the continuing link to oil product prices in Continental European long-term gas contracts? OES NG 19 (2007).http://www. oxfordenergy.org/pdfs/NG19.pdf.

[40] J. Stern, Continental European long-term gas contracts: is a transition away from oil product-linked pricing inevitable and imminent? OES NG 34 (2009).http:/ /www. oxfordenergy.org/pdfs/NG34.pdf.

[41] J. Stern, H.V. Rogers, The transition to Hub-based gas pricing in Continental Europe, OES NG 49 (2011).http://www.oxfordenergy.org/pdfs/NG49.pdf.

[42] R. Weijermars, C. McCredie, Gas pricing - Lifting the price, Petroleum Review 65 (770) (2011) 14-17. 
[43] Z. Chen, P.A. Forsyth, Implications of a regime-switching model on natural gas storage. Under jump diffusion, Review of Derivatives Research 9 (2006) 1-35.

[44] A. Tomasgard, et al., Optimization Models for The Natural Gas Value Chain (2004).http://www.iot.ntnu.no/energy/liberalized_market/optimization\% 20models\%20for\%20the\%20natural\%20gas\%20value\%20chain.pdf.

[45] S.P.A. Brown, M.K. Yucel, Deliverability and regional pricing in US natural gas markets, Energy Economics 30 (5) (2008) 2441-2453.

[46] S.P.A. Brown, M.K. Yucel, Market arbitrage: European and North American natural gas prices, The Energy Journal 30 (2009) 167-185 Special Issue.

[47] Energy Information Administration (EIA), The National Energy Modeling System: An Overview (2009).http://www.eia.gov/oiaf/aeo/overview/.

[48] ENPEP-BALANCE, Energy and Power Balance Evaluation Program. Brief Model Overview-version 2.25 (2008).http://www.dis.anl.gov/pubs/61083.pdf.

[49] National Technical University of Athens (NTUA), The PRIMES Model 2010 (2010).http://www.e3mlab.ntua.gr/e3mlab/PRIMES\%20Manual/The_PRIMES_ MODEL_2010.pdf.

[50] European Commission, Europe 2020 Initiative - Energy Roadmap 2050, Directorate-General for Energy, Brussels (2011).http://ec.europa.eu/energy/ strategies/2011/doc/roadmap_2050/20110503_energy_roadmap_ 2050_state_of_play.pdf.

[51] L.G. Fishbone, H. Abilock, MARKAL, a linear-programming model for energy systems analysis: technical description of the bnl version, Energy Research 5 (1981) $353-375$.

[52] OECD/IEA, Energy Technology Perspectives 2008. Energy Scenarios \& Strategies to 2050, International Energy Agency, Paris, 2008.

[53] OECD/IEA, Energy Technology Perspectives 2010. Energy Scenarios \& Strategies to 2050, International Energy Agency, Paris, 2010.

[54] ETSAP, The Energy Technology Systems Analysis Program (ETSAP) is an Implementing Agreement of the IEA. Details are posted at and at (2011), http://ww. etsap.org, http://www.iea-etsap.org.

[55] R. Loulou, U. Remme, A. Kanudia, A. Lehtila, Goldstein, Documentation for the TIMES Model. Energy Technology Systems Analysis Programme (ETSAP) (2005).http://www.etsap.org/documentation.asp.

[56] ETSAP, International energy Agency implementing agreement for a programme of energy technology systems analysis, in: Gary Goldstein, GianCarlo Tosato (Eds.), Final Report of Annex X (2005-2008), June 2008 (2008) pp. 270.

[57] European Climate Foundation (ECF), Roadmap 2050, a Practical Guide to a Pros perous, Low-carbon Europe (2010).http://www.roadmap2050.eu/attachments/ files/Volume1_fullreport_PressPack.pdf.

[58] D.J.C. MacKay, Sustainable Energy - without the Hot Air (2010).http://www. withouthotair.com/ pp. 364.

[59] DECC, 2050 Pathway Analysis Introduces DECC Energy Scenario 2050 Pathways Calculator Tool, 2010, Department of Energy and Climate Change, 2010, http:// 2050-calculator-tool.decc.gov.uk/.

[60] K. Jiang, X. Hu, X. Zhuang, Q. Liu, Energy Research Institute, National Development and Reform Commission, China's Low-carbon Scenarios and Roadmap for
2050, Sino-Global Energy, June 2009 (2009).http://en.cnki.com.cn/Article_en/ CJFDTOTAL-SYZW200906002.htm.

[61] NARUC, The Renewable Portfolio Standard; A Practical Guide, Prepared for the National Association of Regulatory Utility Commissions. Nancy Rader and Scott Hempling, February 2001 (2001).http://www.naruc.affiniscape.com/ associations/1773/files/rps.pdf p. 92, plus appendices.

[62] EPA, Renewable Portfolio Standards Factsheet (2009).http://www.epa.gov/chp/ state-policy/renewable_fs.html.

[63] R. Wiser, Easing the Natural Gas Crisis: Reducing Natural Gas Prices through Electricity Supply Diversification. Testimony Prepared for a Hearing on Power Generation Resource Incentives \& Diversity Standards Senate Committee on Energy and Natural Resources. March 8, 2005, Lawrence Berkeley National Laboratory, 2005, pp. 7.

[64] R. Wiser, M. Bolinger, M. St. Clair, Easing the Natural Gas Crisis: Reducing Natural Gas Prices through Increased Deployment of Renewable Energy and Energy Efficiency. LBNL-56756, Lawrence Berkeley National Laboratory, Berkeley, California, 2005.http://ectd.lbl.gov/ea/ems/reports/56756.pdf.

[65] S.R. Reeves, G.J. Koperna, V.A. Kuuskraa, Nature and Importance of Technology Progress for Unconventional Gas, Advanced Resources International, Inc, 2007, White Paper, Unconventional Gas Series, July, 2007.

[66] G. Johnson, K. Scholes, R. Whittington, Exploring Corporate Strategy, seventh ed. Prentice Hall, 2005, pp. 635.

[67] H. Mintzberg, B. Ahlstrand, J. Lampel, Strategy Safari, Prentice Hall, 1998, pp. 406.

[68] EOLSS, Artificial Intelligence and Energy Systems: Scope and Definitions Enrico Sciubba (2010).http://www.eolss.net/outlinecomponents/Exergy-Energy-SystemAnalysis-Optimization.aspx.

[69] EOLSS, Present Applications of Artificial Intelligence to Energy Systems Roberto Melli (2010).http://www.eolss.net/outlinecomponents/Exergy-Energy-SystemAnalysis-Optimization.aspx.

[70] European Commission, Energy 2020 - A Strategy for Competitive, Sustainable and Secure Energy (2010).http://ec.europa.eu/energy/strategies/2010/2020 en.htm Brussels, (accessed 10.11.10).

[71] R. Weijermars, Time for Europe to face oil and gas supply realities, First Break 29 (7 (July issue)) (2011) 43-46.

[72] R. Weijermars, Trans-Atlantic energy prices show need for realignment, Oil \& Gas Journal 109 (23 (June 6 issue)) (2011) 26-33.

[73] O. Bahn, N. Edwards, R. Knutti, T.F. Stocker, Energy policies avoiding a tipping point in the climate system, Energy Policy 39 (2011) 334-348.

[74] D. Conner, Managing at the Speed of Change: How Resilient Managers Succeed and Prosper where Others Fail, Villard, New York, 1992.

[75] E.M. Rogers, Diffusion of Innovations, The Free Press, New York, 1995.

[76] J.P. Kotter, H. Rathgeber, Our Iceberg Is Melting: Changing and Succeeding under Any Conditions, Macmillan, New York, 2006.

[77] J.P. Kotter, Organizational Dynamics: Diagnosis and Intervention, Addison-Wesley, New York, 1978 